\title{
Leading the Asset: Resilience training efficacy in UK policing
}

\section{Research Paper}

\section{Key Words}

Policing; Leadership; Resilience; Training; Wellbeing

\begin{abstract}
This paper examines and reports on the efficacy of work-based personal resilience training in a provincial police force in the north of UK. Taking a contextual view, data is modelled from an ASSET survey $(n=350)$ that provides evidence of the manifestations and consequences of providing such input, in comparison with respondents who had no training and were in the same organisation. The findings support the use of such training programs (Hesketh et al., 2015) for improving employee wellbeing and resilience by addressing the sources of stress and educating the workforce in how to deal with these stressors. This research provides compelling evidence that resilient individuals are better equipped to deal with the stressful nature of both policing and an uncertain working environment.
\end{abstract}

This paper posits that effective leadership, a working environment congruent with employee wellbeing, and investment in resilience programmes for the workforce, enhances subsequent organisational performance and is a marker of good practice. 


\section{Introduction}

In a systematic review of workplace resilience training Robertson et al (2015) identified that there had been no meaningful synthesis of resilience training efficacy. The research concluded that resilience training could improve employee performance and wellbeing. This paper seeks to examine the extent to which organisational investment in resilience interventions improves the working life of employees and organisational performance; and is a marker of good professional practice. This is examined through the construct of wellbeing.

The subject organisation is a provincial police force in the north of UK, where a series of multiple cross-sectional surveys have taken place longitudinally in order to probe the efficacy of resilience interventions in the workplace. These interventions consisted of independent classroom-based training sessions that covered the common themes of resilience. These included the ability to cope with the stressors of everyday life, thinking errors and the ability to bounce back following adverse events in the work environment. Surveys were carried out to establish the extent to which the intervention had been effective in terms of general health, attitudes towards work and employee perceptions of their job. These were subsequently compared to employees that had not undergone resilience training, but were in exactly the same working environment.

'A Short Stress Evaluation Tool' (ASSET) was employed to assess sources of stress within respondents. It should be noted that during the course of this research the police force in question was undergoing an unprecedented programme of root and branch reform, involving considerable financial and workforce downsizing. As such, 
the relevance of these findings can be given further significance, in that operational performance has been maintained throughout. This is documented by HMIC inspections on the subject force, which report high performance levels throughout the research period (HMIC, 2015).

\section{Literature}

The literature in this paper seeks to clarify the thinking to date on many of the aspects contained within the findings of this research, beginning with contemporary views on wellbeing. Literature linking Wellbeing to Resilience is then reviewed, covering areas of gender, police culture, mechanisms for measurement and burnout. Finally, the subject of resilience is explored in greater depth, this being the essence of the paper and supporting the notion that it is "an idea whose time has come." (C. L. Cooper, Liu, \& Tarba, 2014).

\section{Wellbeing}

Seligman (2012) outlined his view that Wellbeing is more than the absence of illness. This was supported by Rothmann and Cooper (2015, p.222) with the notion of wellbeing going "beyond the fixed ideas of health as the absence of illness". Seligman argues Wellbeing as a notion has five pillars. These are Positive Emotions, Engagement, Relationships, Meaning and Purpose and Accomplishment (M. Seligman, 2011 p.24). These five areas, commonly referred to as PERMA are measured both objectively and subjectively, and are a development of Seligman's original concept of 'Authentic Happiness' which used life satisfaction as both measures and goals and introduced the notion of flourishing (M. Seligman, 2003). 
These broad headings used by Seligman seem to be widely agreed by a number of wellbeing commentators (C. Cooper \& Robertson, 2012; Kobau et al., 2011; Lyubomirsky, 2010; Carol D. Ryff, 1989). In terms of measuring these descriptions, Ryff \& Keyes (1995) generated a multidimensional model of wellbeing that included six distinct components of positive psychological functioning,

"In combination, these dimensions encompass a breadth of wellness that includes positive evaluation of one's past life (Self-Acceptance), a sense of continued growth and development as a person (Personal Growth), the belief that one's life is purposeful and meaningful (Purpose in Life) the possession of quality relations with others (Positive Relations With Others), the capacity to manage effectively one's life and surrounding world (Environmental Mastery), and a sense of self-determination (Autonomy)”

(Ryff \& Keyes, 1995 p720).

These six dimensions are referred to as the Eudaimonic aspects of psychological wellbeing, when a person is functioning well. In contrast to Hedonic aspects, such as pleasure or the avoidance of pain.

Later measures utilised a wellbeing continuum, ranging from Languishing to Flourishing (Keyes, 2002). Ryff (1989), and also opened the debate around wellbeing and age profiles, arguing that there is a definitive relationship between the two. Ryff's findings are evident in this research, although some of her work speculated beyond working life, 
"It appears that even well educated, healthy economically comfortable older adults face significant challenges in their efforts to maintain as sense of purpose and selfrealization in later life'.

(Ryff, 1989 p.1079)

\section{Gender}

Gender has been discussed endlessly within policing culture (Graaf, 1989; Bethan Loftus, 2009). Ryff's (1989) study included some observations regarding gender, and what she refers to as "women's more troubled psychological profiles." She concluded in her study $(n=321)$ that females had lower levels of internal control and morale, and higher levels of depression. This is balanced by the trends of higher personal growth in women, along with more positive relations with others (Carol D. Ryff, 1989). Theories around 'glass ceiling' popularised by The Wall Street journal article 'The Corporate Woman' (Hymowitz \& Schellhardt, 1986) seek to develop these arguments.

A further cultural debate in policing centres around long hours working and work-life balance, with a particular focus on child care responsibilities and issues around trust as potential bars to promotion for women. Although policing purports to have flexible working arrangements available to all staff, it is generally accepted that females remain in the majority when it comes to requesting flexible contracts, such as reduced hours, or 'fractional' working, as referred to by Gatrell (2007). Whilst flexible working is available to all, there is some scepticism about the career opportunities available to those on flexible contracts as opposed those on full time contracts. Guest (2004) questioned to what extent employees working on flexible contracts were disadvantaged, concluding that knowledge workers on contracts of choice 'pursuing 
boundaryless careers' seem to experience positive outcomes, whilst others experienced less favourable outcomes.

\section{Police Culture}

It should be noted, firstly, that the current culture in policing is not particularly helpful when promoting notions of wellbeing and resilience.

"Police, it is said, have an exaggerated sense of mission towards their role and crave work that is crime oriented and promises excitement. They celebrate masculine exploits, show willingness to use force and engage in informal working practices. Officers are continually suspicious, lead socially isolated lives and display defensive solidarity with colleagues. They are mainly conservative in politics and morality, and their culture is marked by cynicism and pessimism"

(B. Loftus, 2010 p.1).

These elements, described by Loftus (2010), almost form the antipode of stress reduction in the workplace, and form conceptions of living life on the edge. This, again, is unhelpful when promoting the notion of living well and being resilient.

\section{Burnout}

A further challenge to promoting resilience is the culture of burnout, largely associated with long hours of day and night investigations depicted on police television programmes. With its origins as a metaphor used as a colloquial term by poverty lawyers, the term 'burnout' has been described as 'a prolonged response to chronic job stressors' (Maslach, Schaufeli, \& Leiter, 2001 p.405). In this work 
Maslach et al propose there are three dimensions to burnout, Exhaustion, Cynicism and Inefficacy.

Later work by Schaufli (2003) labelled these as Exhaustion, Cynicism or Depersonalisation, and Low Professional Efficacy. The majority of the study concerned jobs that involved caring and services (emotional connections), so is of particular relevance to Policing and the associated professionalisation agenda. On the subject of cynicism the following extract illustrates a policing perspective,

"Moderating one's compassion for clients by emotional distance from them ("detached concern") was viewed as a way of protecting oneself from intense emotional arousal that could interfere with functioning effectively on the job. However, an imbalance of excessive detachment and little concern seemed to lead staff to respond to clients in negative, callous, and dehumanized ways"

(Maslach et al., 2001 p.400).

In relation to this, and to add significance to this argument, policing has been described as an occupation with high emotional labour (C. Cooper, Cartwright, \& Robertson, 2005 p.413).

As well as burnout there is a further stressor on the opposing scale, that of 'rustout' (Palmer \& Cooper, 2010). The theory is that people who become bored by having too little to do or they no longer find the work as challenging may find themselves experiencing stress, anxiety or depression. This introduces the conundrum for many in a managerial role of how much is too much; or too little? Getting the balance right 
between challenge and support, and keeping pressure positive for employees. This is one of the areas contained within the resilience training package. Figure 1 below illustrates the relationship.

\section{INSERT FIGURE 1 ABOUT HERE}

Added to this of course is the fact that we are all unique and have different needs and levels at which we peak, "One person's pressure is another person's stress" (Palmer \& Cooper, 2010 loc 303).

These factors combine to illustrate how much knowledge and understanding is required to keep a team working at their optimum level.

\section{Resilience}

One of the key concepts to understanding where the balance may lie can be explored through the notion of resilience, a critical aspect of Wellbeing.

"Resilience refers to the ability to successfully adapt to stressors, maintaining psychological well-being in the face of adversity"

(Haglund, Nestadt, Cooper, Southwick, \& Charney, 2007 p.899).

The word stems from the Latin resilire - to rebound (Masten, 2014 p.6). Luthans (2002) spoke about the ability to 'bounce back' from adversity; or rebound. The instrument used in this paper (ASSET) proposes four key components of resilience, those being Confidence, Purposefulness, Adaptability and Social Support. The survey reports on the sources of stress in the workplace, and defines stress in this context as,

"When the individual perceives that the demands made upon them exceed their ability to cope..." 
(Cartwright \& Cooper, 2002 p.6).

For individuals who have a supervisory role to play, at whatever level in an organisation, there are additional considerations in relation to how they support and promote individual responses to these aspects; creating a workplace environment where employees can apply these principles and being mindful of signs that all is not well. In support of this proposition a study of the health service in Norway detailed the impact of leadership on sickness absence during a change programme, noting that line manager behaviours directly influenced employee responses (Bernstrøm \& Kjekshus, 2012). Line managers who are both resilient and optimistic provided good leadership. Furthermore, optimism and resiliency are two of the key factors contributing to high levels of psychological capital (PsyCap), hope and self-efficacy being the others. Research suggests that individuals that are high in PsyCap are better equipped to deal with stressors in the workplace due to optimal individual behaviours, performance and attitudes (Luthans, Avolio, \& Avey, 2014). It is particularly relevant within the context of the pace of change in respect of the financial asks (particularly in the UK public sector).

"Employees who are more hopeful, optimistic, efficacious, and resilient may be more likely to 'weather the storm' of the type of dynamic, global environmental contexts confronting most organizations today better than their counterparts with lower PsyCap”

(Luthans et al., 2007 p.568). 
However, in an article aptly entitled 'Prozac Leadership', Collinson (2012) warns of the dangers of leaders becoming almost consumed by optimism and positivity, citing examples on the lead up to the sub-prime mortgage crisis, where the UK Chancellor (Finance Minister) continued to talk in such positive terms about the economy's state of health; almost right up to the point of the collapse. He argues that this excessive positivity, in the face of overwhelming environmental conditions to the contrary, is likely to lead to follower resistance (Collinson, 2012). It has already been well established that leadership plays a critical role, "The more positive an employee's perceptions of top management, the lower his or her rate of increase in absenteeism" (Dello Russo, Miraglia, Borgogni, \& Johns, 2013).

\section{Cost of Sickness}

However, to rely solely on 'sickness absence' as the sign of wellbeing may be flawed, and there are other manifestations such as presenteeism (Johns, 2010) and leaveism (Hesketh \& Cooper, 2014) that may also be indicative of existent workplace problems. In a keynote address to the Good Day at Work Conference, 2012 Ann Francke, the CEO of the Chartered Management Institute (CMI), presented the findings of research carried out by the CMI and Penna (McBain et al., 2012) . This revealed that only 1 in 5 managers have any management qualifications, and $64 \%$ of organisations reported they had no 'need' to train staff in management positions. In the same survey, it is hardly surprising that only $21 \%$ of respondents reported that they consider their line managers to be 'highly effective', with $43 \%$ classing them as 'ineffective' or 'highly ineffective' (Francke, 2012).

The subject of wellbeing, and having a resilient workforce, provides fertile ground for cost savings. With sickness absenteeism costing the UK an estimated $£ 8.4 \mathrm{bn}$, and 
presenteeism $£ 15.1 \mathrm{bn}$ per year (Hutchinson, 2011). For many, this is the focus of effort, the metric that drives activity within the organisation.

"The annual economic costs of sickness absence and worklessness [in the UK] associated with working age ill-health are estimated to be over $£ 100$ billion. This is greater than the current annual budget for the UK's National Health Service and equivalent to the entire GDP of Portugal."

(Black, 2008 p.10).

\section{Measurement}

Wellbeing instruments, such as ASSET (Faragher, Cooper, \& Cartwright, 2004), Stanford Presenteeism Scale (Koopman et al., 2002), the Life Satisfaction Index (Wallace \& Wheeler, 2002), and the Better Life Index (OECD, 2012) can be used to provide supporting evidence to explain sources of stress within the workplace, such as job conditions, job security, attitudes and perceptions; and overall health. Together with absence records, these provide a more 'reality-based' picture of workplace stress, and what the significant impact factors on this landscape are. They also provide organisations with comparative data, affording them the opportunity to position themselves in relation to others. Some studies have distilled further, focussing on specific conditions that result in presenteeism. In a Dutch study of patients with rheumatoid arthritis $(n=237)$ a number of different productivity measures were employed to establish the most valid measurement tool. They concluded that...

"many aspects of presenteeism should be discussed with caution" (Braakman-Jansen, Taal, Kuper, \& van de Laar, 2011 p.359).

New methods, using the same data set, have also been proposed that measure both absenteeism and presenteeism (Bierla, Huver, \& Richard, 2013). These measurement 
instruments, combined with traditional absence measures, provide evidence of organisational and individual behaviours associated with employee wellbeing. More significantly, they also assist in the processes of forming organisational responses (eg wellbeing interventions such as resilience and leadership training programmes) to the issues that emerge. In support of this proposition, research carried out with over 1700 senior executives in the Canadian public sector concluded,

"to reduce the occurrence of presenteeism and absenteeism, employers should avoid concentrating their health promotion activities exclusively on disease-prevention programs"

(Gosselin, Lemyre, \& Corneil, 2013 p.84).

Considerable effort has been devoted to both measuring and understanding workplace stress (Ganster \& Rosen, 2013). Previous work has traditionally used measures of absenteeism, mainly highlighting that general sickness trends have moved from complaints of muscular skeletal related illness to those of stress, anxiety and depression. In a report by the Confederation of British Industry (CBI), the leading voice for businesses in the UK, these are reported as mental illness (CBI, 2011), and have been largely attributed to the general working population shifting to a more knowledge based labour force and away from the manual labour jobs of earlier years. The later introduction of presenteeism (Hutchinson, 2011; Johns, 2010) clearly articulated that the issues of stress in the workplace may not be confined to those employees that were absent due to sickness, arguing the case for being present and sick; amongst other criteria. 


\section{Method}

A series of group-based resilience training sessions took place within the workplace of a police force in the north of the UK. These were conducted by a professional independent company outside of policing. The sessions were predicated on the assumption that resilience is based on personal characteristics and skills that can be learned and developed through appropriate training. The course covered areas that included building personal levels of resilience and managing wellbeing in a workplace setting. The objectives were for participants to understand resilience and to learn how to build and maintain resilience, both in themselves and others. Input on how to recognise signs of stress, what areas of personality help or hinder resilience, and how social support can play a defining role, were all contained within the training programme. The subsequent survey was conducted the following year.

This paper models that data, which was garnered from A Short Stress Assessment Tool, ASSET (Faragher et al., 2004). This wellbeing psychometric instrument is used to measure sources of stress in the workplace. The instrument measures Attitudes Towards the Workplace and Perceptions of the Job. Items capture attitudes and perceptions that are known to cause stress in the workplace, these being Resources and Communications, Control, Work Relationships, Balanced Workloads, Job Security and Change and Job Conditions; known as the 'six essentials' (C. Cooper \& Robertson, 2012). The questionnaire was administered electronically via a Sharepoint platform and employed an online self-reporting approach. Questions on perceptions of the job and attitudes towards the organisation were measured using a six point Likert scale, ranging from 'Strongly Disagree' to 'Strongly Agree'. The Cronbach's alpha reliability score for the 46-item ASSET measure was 0.804 and considered 
acceptable. The study reports on the responses captured from those who underwent resilience training against those who did not, but were in the same working environment.

\section{Findings}

\section{Sample Description}

Three hundred and fifty completed questionnaires were analysed from police officers and staff employed in a provincial police force in the north of the UK. $42 \%$ of respondents were female. 20\% were employed in staff (non-police) or office-based functions. $20 \%$ of respondents were in part-time roles. 48 respondents did not indicate their rank or grade.

\section{Discussion}

Where respondents had undertaken resilience training, there were improvements in scores in all but one of the 6 essential dimensions measured, namely:

- Resources \& Communications,

- Control,

- Work Relationships,

- Balanced Workload,

- Job Conditions.

In the case of the 'Job security and change', there was a decline in respondent perceptions towards how safe their jobs were and how detrimental change was in their work. However, was not significant.

INSERT FIGURE 2 ABOUT HERE 
With regards to Job Security and Change, 3 out of the 5 items that made up this dimension's measure showed significant differences, with two items, 'job security' and 'job changing in the future' declining, and 'the organization changing for changes sake' improving after receiving the resilience training. With these items offsetting each other, resilience training appeared not to have any impact on the essential dimension of 'Job security and change', as illustrated in Table 1. This may be attributable to a realisation that the nature of policing is actually going to change significantly over the coming years, and with further government cuts to policing, job security is actually a realistic worry, especially for police staff. The current projections are for a further $6 \%$ reduction in budgets for the majority of forces by 2020/21 (HMICFRS, 2017).

\section{INSERT TABLE 1 ABOUT HERE}

In the case of Control there was a significant improvement in ASSET scores, with respondents who had attended resilience training having a mean score of $2.87(\mathrm{sd}=$ 0.967), while those respondents who had not undergone resilience training (mean $=$ $3.40, \mathrm{sd}=1.15$ ) felt they had significantly less control of aspects that affect their work than those that had undergone the training $\mathrm{v}(\mathrm{t}=-2.566, \mathrm{df}=348, \mathrm{p}=0.01)$.

Whilst Work Relationships within the force were considered good for all respondents, these improved further amongst respondents who had undergone resilience training. Similarly, respondents who had taken part in resilience training felt their Balanced Workload and their Work-life Balance had improved.

When comparing police staff with police officers, police staff respondents who had undertaken resilience training felt that their Work-life Balance $($ mean $=2.45$, sd $=$ 1.06) was significantly $(\mathrm{t}=2.213, \mathrm{df}=32, \mathrm{p}=0.034)$ better than police officers $($ mean $=3.32, \mathrm{sd}=1.04)$. 
In respect of respondents who had not undergone resilience training, police officers had significantly $(\mathrm{t}=2.315, \mathrm{df}=266, \mathrm{p}=0.021)$ more concerns regarding Balanced Workload $($ mean $=3.37, \mathrm{sd}=0.928)$ than police $\operatorname{staff}($ mean $=2.65 ; \mathrm{sd}=1.0)$.

Police officers who had taken part in resilience training felt that they had significantly $(\mathrm{t}=-2, \mathrm{df}=238, \mathrm{p}=0.43)$ more Control $($ mean $=2.9, \mathrm{sd}=1.0)$ than those officers who had not undergone resilience training (mean $=3.39, \mathrm{sd}=1.08)$. In a similar vein, officers that had undergone resilience training felt significantly better $(\mathrm{t}=-2.2$, df 238 , $\mathrm{p}=0.031)$ about Job Conditions $($ mean $=2.88, \mathrm{sd}=0.72)$ than those that had not $($ mean $=3.28, \mathrm{sd}=0.86)$.

With regard to individual items in ASSET that showed significant differences between police officers that had undergone resilience training and those that had not, the following items illustrated in Table 2 showed significant improvement.

\section{INSERT TABLE 2 ABOUT HERE}

With regard to police staff, there were no significant differences amongst any of the essential dimensions from ASSET. There were however 4 individual items that showed significant improvements, namely; Control Over Aspects of their Job (Control), their Work Being Dull and Repetitive (Job Conditions), not being Adequately Trained (Resources \& Communications) and being more Willing to Put Themselves Out for the Force (Engagement).

33 out of the 46 items measured (72\%) in ASSET showed improvement with male respondents who had undertaken resilience training. Of these 2 were significant 
improvements (I have little control over many aspects of my job and My organization is changing for change's sake).

With 'My job is likely to change in the future', this item showed a significant increase $(\mathrm{t}=1.60, \mathrm{df}=200, \mathrm{p}=0.002)$. This however need not be a stress inducer, but recognition of the changing roles that exist in policing.

Like their male colleagues, females reported 33 items from ASSET showing improvement after resilience training (72\%), with 4 showing significant differences between respondents that had undergone resilience training and those that had not. 'My physical working conditions are unpleasant', 'I have little or no influence over my performance targets' and 'Outside of my particular job, I take an interest in many aspects of the running and success of this organisation' all showed significant improvements. Job Security showed a significant decline.

However, in terms of resilience, this study noted significantly lower (better) scores for women in stressors such as Work-life Balance - males mean score $=3.5 s d=1.1$ females mean score $=3.2 s d=1.1$ for females $(t=2.8, d f=346, p=0.05)$ and $J_{o b}$ Conditions - males mean score $=3.2, s d=0.8$ females mean score $=3.0 s d=0.8 \quad(t=2.5$, $d f=346, p=0.015)$. This is in contrast to Ryff's (1989) study, which included observations that females had lower levels of internal control. The results of this study, however, model significantly better scores for women in items such as Worklife Balance and Job Conditions. A detailed inventory of all the mean scores is provided at Appendix 1 below.

\section{Conclusions}

Robertson et al (2015) noted that the empirical evidence for resilience training efficacy is tentative. This study clearly shows that, in a policing context, resilience 
training is highly effective and can contribute towards positive wellbeing outcomes. Furthermore, we argue that resilience, as measured with ASSET, can provide a good indicator of officer and staff wellbeing. Wellbeing, as recognised by the HMICFRS, is a key indicator of operational effectiveness and legitimacy. As such, and congruent with the professionalisation agenda, wellbeing provides a clear indicator of good professional practice.

As discussed, policing culture seems to contribute to many of the areas that identify sources of stress, almost adding to the issue with the way policing has developed. This is clearly unhelpful, and a recommendation would be that cultural awareness should be included within training programmes. Especially in such customer facing roles that are viewed as confrontational, and as such are high in emotional labour. These considerations highlight further the effectiveness of this intervention.

This research clearly shows improvements in relation to measures of Resources \& Communications, Control, Work Relationships, Balanced Workload, Work-life Balance, and Job Conditions in respondents who had undertaken resilience training. A proposal would be that resilience training ought to be incorporated into Leadership inputs, with the aim of better preparing leaders for the pressures and challenges of the modern working environment. Within $[\mathrm{UK}]$ policing, a period of unprecedented change in almost all aspects of the occupation has amplified the urgency for this to take place.

Further research into police-specific resilience training programmes, and links to police leadership is needed to optimise efficacy. However, this research illustrates how resilience training can dramatically improve many aspects of working life for those in policing. To conclude, 
"Concerns about individual and organisational resilience are now centre stage in human resource management and occupational psychology, not only to enhance productivity but also to foster workplace wellbeing and engagement." (Robertson, Cooper, Sarkar, \& Curran, 2015 p.27). 


\section{References}

Bernstrøm, V. H., \& Kjekshus, L. E. (2012). Leading during change: the effects of leader behavior on sickness absence in a Norwegian health trust. BMC Public Health, 12, 799-799. doi:10.1186/1471-2458-12-799

Bierla, I., Huver, B., \& Richard, S. (2013). New evidence on absenteeism and presenteeism. The International Journal of Human Resource Management, 24(7), 1536-1550. doi:10.1080/09585192.2012.722120

Black, C. (2008). Working for a healthier tomorrow. Retrieved from

Braakman-Jansen, L. M. A., Taal, E., Kuper, I. H., \& van de Laar, M. A. F. J. (2011). Productivity loss due to absenteeism and presenteeism by different instruments in patients with RA and subjects without RA. Rheumatology, 51(2), 354-361. doi:10.1093/rheumatology/ker371

Cartwright, S., \& Cooper, C. (2002). ASSET: Management Guide. In. Manchester UK: RobertsonCooper Ltd.

CBI. (2011). Healthy returns? Absence and workplace health survey 2011 (978-0-85201726-5). Retrieved from

Collinson, D. (2012). Prozac Leadership and the limits of positive thinking. Leadership, $8(2), 87-107$.

Cooper, C., Cartwright, S., \& Robertson, S. (2005). Work Environments, Stress, and Productivity: An examination using ASSET. International Journal of Stress Management, Vol 12, 4, 409-423.

Cooper, C., \& Robertson, I. (Producer). (2012). Workplace Well-being. Robertson Cooper. Retrieved from http://www.robertsoncooper.com/what-we-do/the-6-essentialsof-workplace-well-being

Cooper, C. L., Liu, Y., \& Tarba, S. Y. (2014). Resilience, HRM practices and impact on organizational performance and employee well- being: International Journal of Human Resource Management 2015 Special Issue. The International Journal of Human Resource Management, 25(17), 2466-2471. doi:10.1080/09585192.2014.926688

Dello Russo, S., Miraglia, M., Borgogni, L., \& Johns, G. (2013). How time and perceptions of social context shape employee absenteeism trajectories. Journal of Vocational Behavior, 83(2), 209-217. doi:10.1016/j.jvb.2013.03.005

Faragher, E. B., Cooper, C. L., \& Cartwright, S. (2004). A shortened stress evaluation tool (ASSET. Stress and Health, 20, 189-201. doi:10.1002/smi.1010

Francke, A. (2012). Ann Francke's keynote speech. Paper presented at the Good Day at Work Well-being professionals' annual conference, London.

Ganster, D. C., \& Rosen, C. C. (2013). Work Stress and Employee Health. Journal of Management, 39(5), 1085-1122. doi:10.1177/0149206313475815

Gatrell, C. (2007). A fractional commitment? Part-time work and the maternal body. International Journal of Human Resource Management, 18(3), 462-475.

Gosselin, E., Lemyre, L., \& Corneil, W. (2013). Presenteeism and Absenteeism. Journal of Occupational Health Psychology, 18(1), 75-86. doi:10.1037/a0030932

Graaf, R. (1989). Talking Blues. London: Collins Harvill.

Guest, D. (2004). Flexible employment contracts, the psychological contract and employee outcomes: an analysis and review of the evidence. International Journal of Management Reviews, 5/6(1), 1-19.

Haglund, M. E. M., Nestadt, P. S., Cooper, N. S., Southwick, S. M., \& Charney, D. S. (2007). Psychobiological mechanisms of resilience: Relevance to prevention and treatment of stress-related psychopathology. Dev Psychopathol, 19(3), 889-920. doi:10.1017/S0954579407000430

Hesketh, I., \& Cooper, C. (2014). Leaveism at Work. Occupational Medicine, 64(3), 146147. 
HMIC. (2015). Police Force Inspections UK. Retrieved from Online: https://www.justiceinspectorates.gov.uk/hmic/our-work/

HMICFRS. (2017). Significantly stressed police forces need to continue to change. Retrieved from https://www.justiceinspectorates.gov.uk/hmicfrs/news/newsfeed/significantly-stressed-forces-need-to-continue-to-change/

Hutchinson, J. (2011). Prenteeism. Sainsbury Centre for Mental Health. Retrieved from http://www.centreformentalhealth.org.uk/training/why_working_late.aspx

Hymowitz, C., \& Schellhardt, T. (1986, 24/03/1986). The glass ceiling. The wall Street Journal.

Johns, G. (2010). Presenteeism in the workplace: A review and research agenda. Journal of Organizational Behavior Vol 31 Issue 4, 519-542.

Keyes, C. (2002). The mental health continuum: From languishing to flourishing in life. Journal of Health and Social Behaviour, 43, 207-222.

Kobau, R., Seligman, M. E. P., Peterson, C., Diener, E., Zack, M. M., Chapman, D., \& Thompson, W. (2011). Mental health promotion in public health: perspectives and strategies from positive psychology. American journal of public health, 101(8), 1-9. doi:10.2105/AJPH.2010.300083

Koopman, C., Pelletier, K., Murray, J., Sharda, C., Berger, M., Turpin, R., ... Bendel, T. (2002). Stanford presenteeism scale: health status and employee productivity. Journal of occupational and environmental medicine, 44(1), 14-20.

Loftus, B. (2009). Police Culture in a Changing World. New York: Oxford University Press.

Loftus, B. (2010). Police occupational culture: classic themes, altered times. Polic. Soc., 20(1), 1-20. doi:10.1080/10439460903281547

Luthans, F., Avolio, B. J., \& Avey, J. B. (2014). The Left Side of Psychological Capital. Journal of Leadership \& Organizational Studies, 21(2), 141-149. doi:10.1177/1548051813515516

Lyubomirsky, S. (2010). The how of happiness : a practical approach to getting the life you want. London: Piatkus.

Maslach, C., Schaufeli, W., \& Leiter, M. P. (2001). Job Burnout. Annual Review of Psychology, 52, 397-422.

Masten, A. S. (2014). Global Perspectives on Resilience in Children and Youth. Child Development, 85(1), 6-20. doi:10.1111/cdev.12205

McBain, R., Ghobadian, A., Switzer, J., Wilton, P., Woodman, P., \& Pearson, G. (2012). The Business Benefits of Management and Leadership Development (0-85946-492-X). Retrieved from

OECD. (2012). Organisation for Economic Cooperation and Development - Better Life Index. Retrieved from www.oecdbetterlifeindex.org

Palmer, S., \& Cooper, C. L. (2010). How to deal with stress (2nd ed. ed.). London: Kogan Page.

Robertson, I., Cooper, C., Sarkar, M., \& Curran, T. (2015). Resilience training in the workplace from 2003 to 2014: A systematic review. Journal of Occupational Psychology. doi:10:11 11/joop.12120

Ryff, C. D. (1989). Happiness Is Everything, or Is It? Explorations on the Meaning of Psychological Well-Being. Journal of Personality and Social Psychology, 57(6), 1069-1081. doi:10.1037/0022-3514.57.6.1069

Ryff, C. D., \& Keyes, C. L. (1995). The structure of psychological well-being revisited. Journal of personality and social psychology, 69(4), 719.

Schaufeli, W. (2003). Past performance and future perspectives of burnout research. South African Journal of Industrial Psychology, 29(4), 1-15.

Seligman, M. (2003). Authentic happiness : using the new positive psychology to realize your potential for deep fulfillment. London: Nicholas Brealey.

Seligman, M. (2011). Flourish : a new understanding of happiness and well-being - and how to achieve them. London: Nicholas Brealey Publishing. 
Seligman, M. (2012). Science of Wellbeing: More than the absence of illness. In Conference address at The Hilton, Adelaide 24/02/2012.

Wallace, K. A., \& Wheeler, A. J. (2002). Reliability Generalization of the Life Satisfaction Index. Educational and Psychological Measurement, 62(4), 674-684.

Yerkes, R., \& Dodson, J. (1908). THE RELATION OF STRENGTH OF STIMULUS TO RAPIDITY OF HABIT-FORMATION. Journal of Comparative Neurology and Psychology, 18, 459-482, 18(1), 459-482. 
Figures and Tables

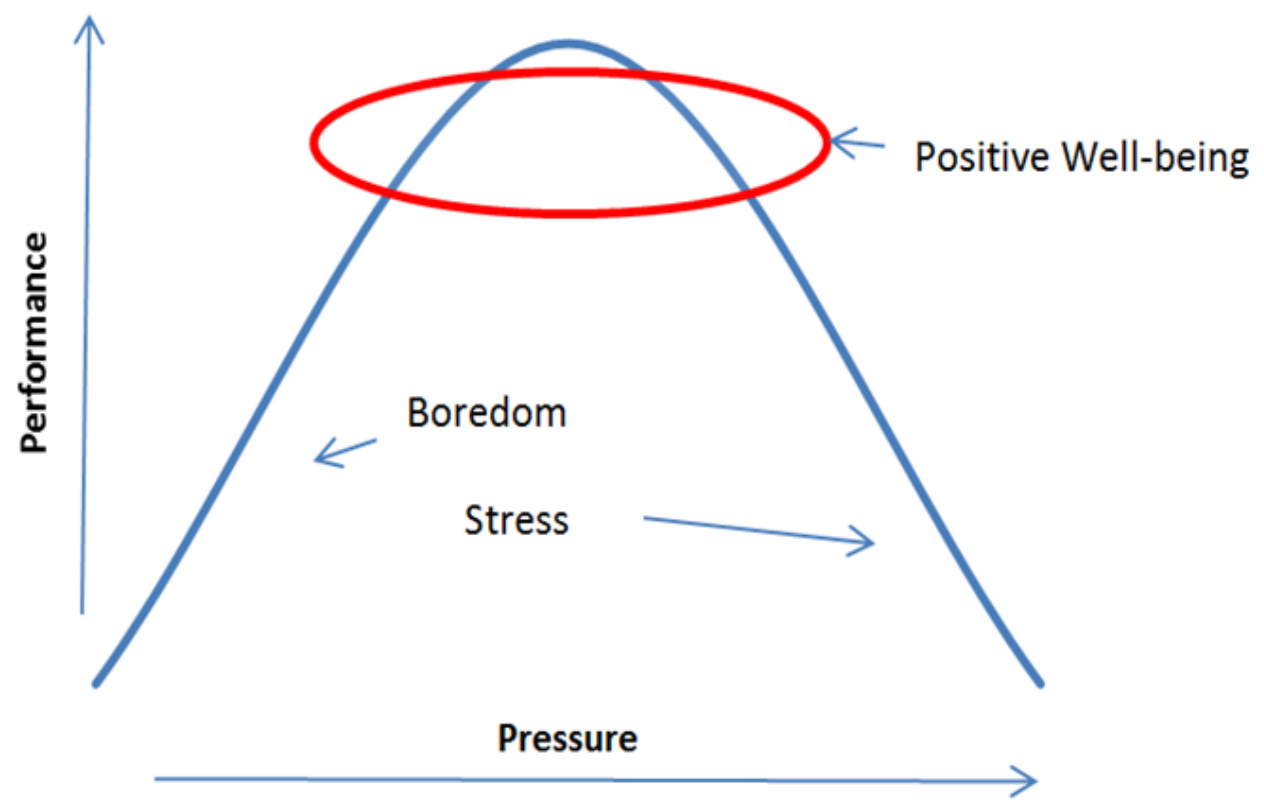

Figure 1- Performance Pressure Relationship (adapted fromYerkes \& Dodson, 1908)

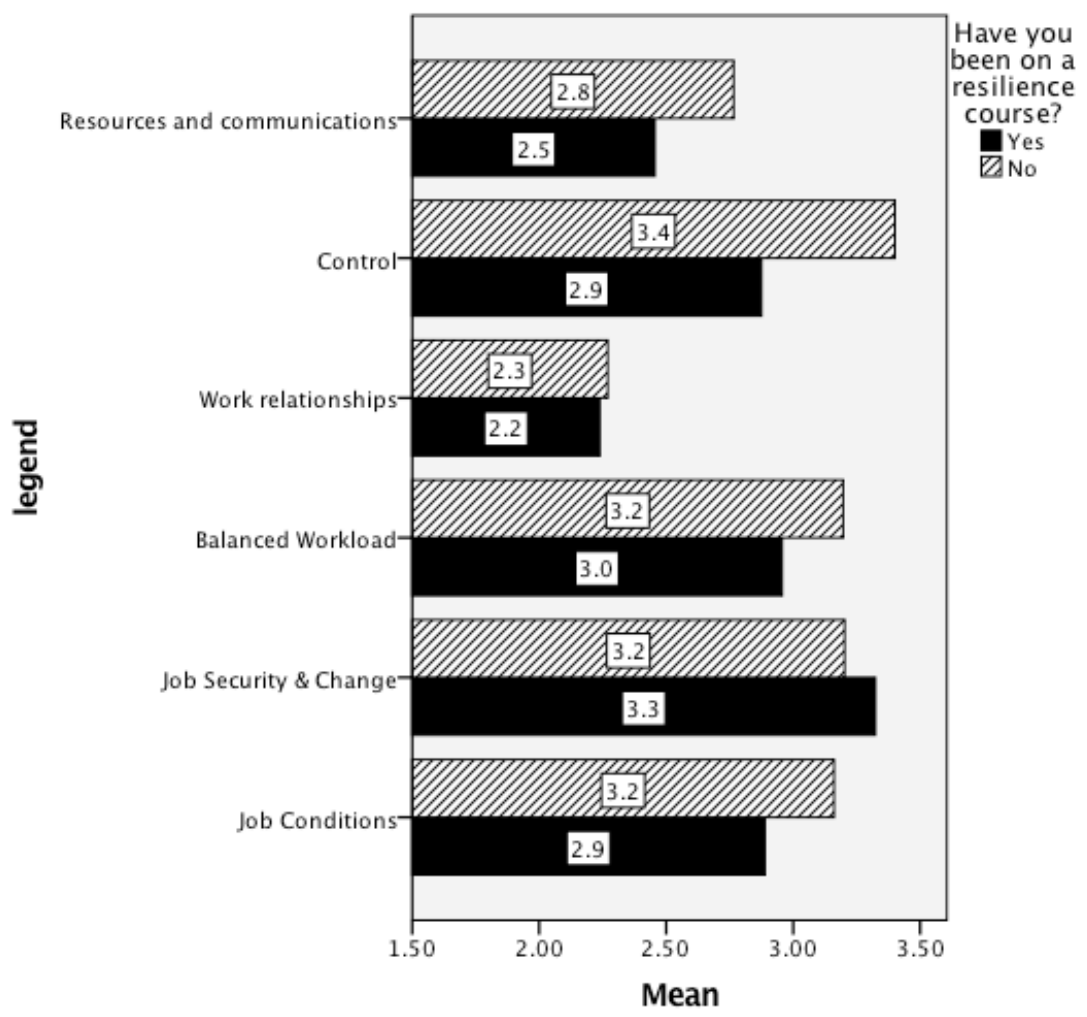

Figure 2 - ASSET scores for Resilience Training vs No Resilience Training 


\begin{tabular}{|c|c|c|c|c|c|c|c|}
\hline Item & $\begin{array}{l}\text { Resilience } \\
\text { Training } \\
\end{array}$ & Mean & sd & $\mathrm{t}$ & $\mathrm{df}$ & $\mathrm{p}$ & Change \\
\hline \multirow[t]{2}{*}{ Job security \& change } & Yes & 3.32 & 0.83 & \multirow[t]{2}{*}{0.741} & \multirow[t]{2}{*}{348} & \multirow[t]{2}{*}{0.46} & \multirow[t]{2}{*}{ No change } \\
\hline & No & 3.20 & 0.912 & & & & \\
\hline \multirow[t]{2}{*}{ My job in insecure } & Yes & 3.47 & 1.83 & \multirow[t]{2}{*}{2.33} & \multirow[t]{2}{*}{346} & \multirow[t]{2}{*}{0.02} & \multirow[t]{2}{*}{ Reduced } \\
\hline & No & 2.79 & 1.61 & & & & \\
\hline \multirow[t]{2}{*}{ My job is not permanent } & Yes & 2.68 & 1.57 & 1.35 & \multirow[t]{2}{*}{348} & \multirow[t]{2}{*}{0.17} & \multirow[t]{2}{*}{ No change } \\
\hline & No & 2.30 & 1.52 & 1.32 & & & \\
\hline \multirow[t]{2}{*}{ My job is likely to change in the future } & Yes & 5.09 & 1.03 & \multirow[t]{2}{*}{2.06} & \multirow[t]{2}{*}{348} & \multirow[t]{2}{*}{0.04} & \multirow[t]{2}{*}{ Reduced } \\
\hline & No & 4.61 & 1.30 & & & & \\
\hline \multirow{2}{*}{$\begin{array}{l}\text { My organization is constantly changing } \\
\text { for changes sake }\end{array}$} & Yes & 3.18 & 1.42 & \multirow[t]{2}{*}{-2.51} & \multirow[t]{2}{*}{348} & \multirow[t]{2}{*}{0.01} & \multirow[t]{2}{*}{ Improved } \\
\hline & No & 3.87 & 1.54 & & & & \\
\hline
\end{tabular}

Table 1 - Job Security and Change

\begin{tabular}{|c|c|c|c|c|c|c|c|}
\hline Item & $\begin{array}{l}\text { Resilience } \\
\text { Training }\end{array}$ & Mean & sd & $\mathrm{t}$ & $\mathrm{df}$ & $\mathrm{p}$ & Change \\
\hline \multirow[t]{2}{*}{ Control } & Yes & 2.92 & 1.04 & \multirow[t]{2}{*}{-2.0} & \multirow[t]{2}{*}{238} & \multirow[t]{2}{*}{0.04} & \multirow[t]{2}{*}{ Improved } \\
\hline & No & 3.39 & 1.08 & & & & \\
\hline \multirow[t]{2}{*}{ Job conditions } & Yes & 2.88 & 0.72 & \multirow[t]{2}{*}{-2.2} & \multirow[t]{2}{*}{238} & \multirow[t]{2}{*}{0.03} & \multirow[t]{2}{*}{ Improved } \\
\hline & No & 3.28 & 0.86 & & & & \\
\hline \multirow{2}{*}{$\begin{array}{l}\text { I have little control over many aspects of my } \\
\text { job }\end{array}$} & Yes & 3.25 & 1.42 & \multirow[t]{2}{*}{-2.1} & \multirow[t]{2}{*}{237} & \multirow[t]{2}{*}{0.04} & \multirow[t]{2}{*}{ Improved } \\
\hline & No & 3.88 & 1.41 & & & & \\
\hline \multirow{2}{*}{$\begin{array}{l}\text { My job involves the risk of actual physical } \\
\text { violence }\end{array}$} & Yes & 3.04 & 1.85 & \multirow[t]{2}{*}{-2.7} & \multirow[t]{2}{*}{337} & \multirow[t]{2}{*}{0.01} & \multirow[t]{2}{*}{ Improved } \\
\hline & No & 4.07 & 1.78 & & & & \\
\hline \multirow[t]{2}{*}{ My job is likely to change in the future } & Yes & 5.08 & 0.97 & \multirow[t]{2}{*}{2.065} & \multirow[t]{2}{*}{348} & \multirow[t]{2}{*}{0.04} & \multirow[t]{2}{*}{ Reduced } \\
\hline & No & 4.59 & 1.30 & & & & \\
\hline \multirow{2}{*}{$\begin{array}{l}\text { My organization is constantly changing for } \\
\text { changes sake }\end{array}$} & Yes & 3.08 & 1.50 & \multirow[t]{2}{*}{-2.51} & \multirow[t]{2}{*}{348} & \multirow[t]{2}{*}{0.01} & \multirow[t]{2}{*}{ Improved } \\
\hline & No & 3.88 & 1.53 & & & & \\
\hline \multirow{2}{*}{$\begin{array}{l}\text { I have little or no influence over my } \\
\text { performance targets }\end{array}$} & Yes & 2.75 & 1.48 & \multirow[t]{2}{*}{-2.2} & \multirow[t]{2}{*}{237} & \multirow[t]{2}{*}{0.03} & \multirow[t]{2}{*}{ Improved } \\
\hline & No & 3.46 & 1.53 & & & & \\
\hline \multirow[t]{2}{*}{ My job is not permanent } & Yes & 2.79 & 1.69 & \multirow[t]{2}{*}{2.19} & 238 & 0.03 & Reduced \\
\hline & No & 2.12 & 1.40 & & & & \\
\hline
\end{tabular}

Table 2 - Items showing significant differences between police officers who had resilience training and those who had not

\section{Appendix 1: Mean scores of those who attended Resilience Training and those}

who did not.

\section{Resources and Communications}

I do not feel I am informed about what is going on in this organisation

I am never told if I am doing a good job

I am not adequately trained to do many aspects of my job

I do not have the proper equipment or resources to do my job

Attended a

Resilience course

Yes

No

\begin{tabular}{|l|l|}
\hline $\mathbf{2 . 4 5 8}$ & $\mathbf{2 . 8 2 0}$ \\
\hline 2.500 & 2.970 \\
\hline 2.590 & 3.100 \\
\hline 2.180 & 2.320 \\
\hline 2.560 & 2.890 \\
\hline
\end{tabular}

Control* $^{*}$ 
I have little control over many aspects of my job*

I am not involved in decisions affecting my job

My ideas or suggestions about my job are not taken into account

I have little or no influence over my performance targets*

\begin{tabular}{|l|l|}
2.940 & 3.890 \\
\hline 3.440 & 3.700 \\
\hline 2.500 & 2.960 \\
\hline 2.620 & 3.460 \\
\hline
\end{tabular}

\section{Work relationships}

My boss behaves in an intimidating and bullying way towards me

I do not receive the support from others (boss/colleagues) that I would like

I feel isolated at work e.g. working on my own or lack of social support from others

I am not sure what is expected of me by my boss

Other people at work are not pulling their weight

My boss is forever finding fault with what I do

Others take the credit for what I have achieved

My relationships with colleagues are poor

\begin{tabular}{|l|l|}
\hline $\mathbf{2 . 2 4 0}$ & $\mathbf{2 . 2 7 4}$ \\
\hline 1.590 & 1.600 \\
\hline 2.470 & 2.680 \\
\hline 2.150 & 2.410 \\
\hline 2.000 & 2.070 \\
\hline 3.590 & 3.510 \\
\hline 1.590 & 1.620 \\
\hline 2.740 & 2.650 \\
\hline 1.790 & 1.650 \\
\hline
\end{tabular}

\section{Balanced Workload}

\section{Work life balance}

I work longer hours than I choose or want to

I work unsociable hours e.g. weekends, shift work etc

I spend too much time travelling in my job

My work interferes with my home and personal life

\section{Workload}

The technology in my job has overloaded me

I am set unrealistic deadlines

I am given unmanageable workloads

I do not have enough time to do my job as well as I would like

\begin{tabular}{|l|l|}
\hline 2.956 & $\mathbf{3 . 1 8 9}$ \\
\hline 3.068 & $\mathbf{3 . 4 2 0}$ \\
\hline 2.910 & 3.340 \\
\hline 3.210 & 3.780 \\
\hline 2.410 & 2.570 \\
\hline 3.740 & 3.990 \\
\hline 2.845 & $\mathbf{2 . 9 5 8}$ \\
\hline 2.180 & 2.460 \\
\hline 2.470 & 2.610 \\
\hline 2.940 & 2.900 \\
\hline 3.790 & 3.860 \\
\hline
\end{tabular}

\section{Job Security \& Change}

My job is insecure*

My job is not permanent

My job is likely to change in the future*

My job skills may become redundant in the near future

My organisation is constantly changing for change's sake*

\section{Job Conditions*}

I may be doing the same job for the next 5 to 10 years

My physical working conditions are unpleasant (e.g. noisy, dirty, poorly designed).

My job involves the risk of actual physical violence*

My performance at work is closely monitored

My work is dull and repetitive

I have to deal with difficult customers/clients

I do not enjoy my job

My pay \& benefits are not as good as other people doing the same or similar work

\begin{tabular}{|l|l|}
\hline $\mathbf{3 . 3 3 0}$ & $\mathbf{3 . 2 8 0}$ \\
\hline 3.470 & 2.880 \\
\hline 2.680 & 2.330 \\
\hline 5.090 & 4.640 \\
\hline 2.210 & 2.470 \\
\hline 3.180 & 4.040 \\
\hline
\end{tabular}

\begin{tabular}{|l|l|}
\hline $\mathbf{2 . 8 7 6}$ & $\mathbf{3 . 2 4 6}$ \\
\hline 3.590 & 3.570 \\
\hline 2.290 & 2.750 \\
\hline 2.880 & 3.840 \\
\hline 3.320 & 3.610 \\
\hline 1.880 & 2.300 \\
\hline 4.290 & 4.410 \\
\hline 1.910 & 2.260 \\
\hline 2.850 & 3.230 \\
\hline
\end{tabular}


* Significant differences between respondents who attended a resilience course and those that had not. 